\title{
Pain and temporomandibular disorders in patients with eating disorders
}

\section{Samanta Pereira de SOUZA(a) Reynaldo ANTEQUERDDS(a) Eduardo Wagner ARATANGY(a) Silvia Regina Dowgan Tesseroli de SIQUEIRA(a) \\ Táki Athanássios CORDÁS(a) José Tadeu Tesseroli de SIQUEIRA ${ }^{(b)}$}

(a) Universidade de São Paulo - USP, Medical School, Psychiatric Institute,

São Paulo, SP, Brazil.

(b) Universidade de São Paulo - USP, Medical School, Department of Neurology, São Paulo, SP, Brazil.
Declaration of Interest: The authors certify that they have no commercial or associative interest that represents a conflict of interest in connection with the manuscript.

\section{Corresponding Author:}

José Tadeu Tesseroli de Siqueira

E-mail: jose.ttsiqueira@hc.fm.usp.br

https://doi.org/10.1590/1807-3107bor-2018.vol32.0051
Submitted: November 17, 2017

Accepted for publication: April 10, 2018

Last revision: May 03, 2018
Abstract: Orofacial pain and temporomandibular dysfunction may cause chronic facial pain, which may interfere with the emotional state and food intake of patients with eating disorders (ED), such as anorexia nervosa (AN) and bulimia nervosa (BN). Sixty-four patients were assigned to four groups: Group A (AN - restricting subtype): 07; Group B (AN - purging subtype ): 19; Group C (BN): 16; and Group D (control): 22. Complaints of pain are more prevalent in individuals with eating disorders $(\mathrm{p}<0.004)$. There are differences between the presence of myofascial pain and the number of hospitalizations $(p=0.046)$ and the presence of sore throat $(p=0.05)$. There was a higher prevalence of masticatory myofascial pain and complaints of pain in other parts of the body in ED patients; however, there was no difference between ED subgroups. There was no difference in the number of self-induced vomiting between ED patients with and without myofascial pain.

Keywords: Feeding and Eating Disorders; Facial Pain;

Temporomandibular Joint Disorders; Anorexia Nervosa; Bulimia Nervosa.

\section{Introduction}

Eating disorders (EDs) are a group or psychiatric disorders that have severe consequences for the body, and anorexia nervosa (AN) and bulimia nervosa $(\mathrm{BN})$ stand out as the main EDs. ${ }^{1}$

AN has a prevalence of $0.5 \%$ and is characterized by deliberate weight loss through extremely strict diets in pursuit of thinness, ${ }^{2,3,4,5,6,7}$ and the result varies from spontaneous recovery to an oscillating course to death. ${ }^{8}$ Weight loss can occur through restricted diets only (anorexia nervosa - restricting subtype) or through the association of diet with purging methods (anorexia nervosa - purging subtype), such as self-induced vomiting and use of medications (diuretics, appetite suppressants, laxatives), diet, and physical exercise. ${ }^{5,6,7} \mathrm{BN}$, in turn, has a prevalence of $1 \%$ and is characterized by large food intake accompanied by feelings of loss of control and inappropriate compensatory methods for weight control, such as self-induced vomiting, use of medications (diuretics, appetite suppressants, laxatives), diet, and physical exercise. ${ }^{2,3,4,7}$ The pathogenesis of ED is multifactorial, involving psychological, biological, and sociocultural factors. ${ }^{8,9}$ Malnutrition produces endocrine and metabolic changes and alters bodily functions, causing hematologic, skeletal, neuropsychiatric, gastrointestinal, dermatological, metabolic, and dental changes. ${ }^{8}$ 
Food intake and general well-being are key factors for a better prognosis of ED patients. The recognition of the oral status of ED patients is critical, since the symptoms of oral diseases can inform about the progression of this psychiatric illness as well as about the patient's general health. ${ }^{10,11}$ Dentists can contribute to the diagnosis of ED because they are probably one of the first health professionals to have contact with this group of patients. ${ }^{11,12}$

It is also known that oral status can be greatly affected by the behavior of the patient and by physiological changes to the orofacial region, which vary from salivary imbalance to damage to the musculoskeletal system and to the presence of pain. The oral status of these patients can affect them emotionally, making eating even more difficult and further compromising their nutritional status.

EDs and their correlation with chronic orofacial pain and temporomandibular disorders (TMD) have been described in recent studies, whose findings indicate a high prevalence of signs and symptoms of TMDs $^{11,13}$ and of chronic facial pain. ${ }^{14}$ Also, another study showed an important correlation between complaints of pain and depression in ED patients. ${ }^{14}$ Therefore, ED patients generally constitute a complex group that often requires dental care. ${ }^{10,15,16}$ In addition, dentists have limited clinical experience with these patients and lack sufficient knowledge of the correlation between ED and oral health. ${ }^{16}$ In our orofacial pain group, ED patients frequently seek dental care because of orofacial pain.

Therefore, the purpose of this study was to determine the prevalence of facial pain and of pain in other regions of the body as well as the prevalence of masticatory pain based on the RDC/ TMD questionnaire of ED patients followed up at a psychiatric hospital. Based on this information, it is possible to devise multidisciplinary strategies for regular dental evaluation of these patients and for a more effective orofacial pain control.

\section{Methodology}

This was a cross-sectional study. The clinical evaluation was performed at the outpatient clinic of the Dental Clinic of the Institute of Psychiatry of the Hospital das Clínicas, affiliated with the Faculty of Medicine of the University of São Paulo. All patients were subjected to a standardized clinical protocol applied by only one trained dentist specialized in orofacial pain and ED.

The study included male and female ED patients older than 18 years who agreed to participate in the research and who met the clinical criteria and who were being treated at the Eating Disorders Program of the Institute of Psychiatry (AMBULIM). All patients had been diagnosed with ED and other comorbidities by specialized psychiatrists of the Eating Disorders Program of the Institute of Psychiatry (AMBULIM) using the DSM-V and ICD 10.

Sixty-four patients were assigned to four groups according to their psychiatric diagnosis: Group A (anorexia nervosa - restricting subtype): 7 patients; Group B (anorexia nervosa - purging subtype): 19 patients; Group C (bulimia nervosa): 16 patients; and Group D (control group): 22 patients. Group D was randomized and consisted of individuals without a diagnosis of psychiatric disorders and whose age and social status were the same as those of groups A, B, and C. None of the control patients was on medication. Groups $B$ and C, which were composed of patients who engaged in purging, were divided into subgroups according to the number of self-induced vomiting episodes per day.

$\mathrm{ED}$ and control patients were excluded if they were being treated for chronic grinding or clenching of the teeth and/or had orofacial pain, temporomandibular dysfunction, maxillary neoplasm, or infection.

The clinical protocol consisted of:

a. Standardized assessment by the Orofacial Pain Team of Hospital das Clínicas, affiliated with the Faculty of Medicine of the University of São Paulo (EDOF-HC): $:^{17}$ interview and systematic evaluation of cervical, cranial, facial, dental, and other oral structures for obtaining the following information: A) main complaint; B) general characteristics of the pain (location, intensity, quality, duration, periodicity, worsening, and improvement factors); C) clinical history of the patient, including comorbidities, medication in use, headache, and complaints of pain in other regions of the body; D) physical examination of the cervical, cranial, facial, and intraoral regions; and E) panoramic radiography of the face.

b. The Portuguese Validated Version of the Research Diagnostic Criteria for Temporomandibular Disorders (RDC/TMD) questionnaire. ${ }^{18,19}$ 
c. The medical records of the patients.

d. Diagnosis of tooth erosion according to clinical evaluation of tooth surfaces. ${ }^{20}$

e. The research project was approved by the Medical School Ethics Committee (Hospital das Clínicas, Universidade de São Paulo, process number 435.656) and all patients signed an informed consent form.

\section{Statistical analysis}

Categorical variables were presented descriptively in tables containing absolute (n) and relative (\%) frequencies. The association between these variables and the groups (A, B, C, and D) were evaluated by the likelihood test. The variables with normal distribution were presented with mean and standard deviation using analysis of variance (ANOVA). Those variables without normal distribution were subjected to the Kruskal-Wallis test. In case of statistical significance, Dunn's test was used to determine the differences between the groups ${ }^{21}$ The variables with $p<0.10$ were included in the multiple logistic regression model for evaluation of the predictors of myofascial pain. In all statistical calculations, the level of significance was set at $p \leq 0.05$ The data were stored and evaluated using SPSS (Statistical Package for Social Sciences) version 18 (SPSS, Inc., Chicago, IL, USA).

\section{Results}

Demographic and general characteristics are shown in Table 1. There were no significant differences in age between the groups $(\mathrm{p}=0.062)$. There were differences in educational level $(p=0.007)$ and in inactive work status $(p=0.009)$. There were no gender differences $(84.5 \%$ of the patients were women and $15.5 \%$ were men $)(p=0.300)$ and no differences in marital status $(p=2.272)$.

Nearly one third of the total ED sample (28.5\%) was away from work, either receiving government sickness allowance (INSS) or on medical leave. There was a significant difference with the control group $(\mathrm{p}=0.009)$.

There were differences between groups $\mathrm{A}, \mathrm{B}$, and $\mathrm{C}$ regarding the duration of ED in years $(p<0.001)$, but no differences regarding psychiatric comorbidities, use of medication, and use of illicit drugs (Table 2).

There were significant differences $(\mathrm{p}=0.001)$ in body mass index (BMI) between the groups, with the lowest mean prevalence among individuals in groups $A$ and $\mathrm{B}(\mathrm{BMI}=18)$, and the highest mean among individuals in group $\mathrm{C}(\mathrm{BMI}=30)$. Group $\mathrm{D}$ showed values within normal limits $(\mathrm{BMI}=22)$, according to $\mathrm{WHO}$.

Groups B and C had more than one self-induced vomiting episode per day. This practice was absent in groups $\mathrm{A}$ and $\mathrm{D}$.

Table 1. Demographic and general characteristics $(n=64)$.

\begin{tabular}{|c|c|c|c|c|c|}
\hline Variable & Group A $(n=7)$ & Group B (n= 19) & Group C $(n=16)$ & Group D $(n=22)$ & $P$ \\
\hline Age (years) & $37(20-47)$ & $33(25-40)$ & $33(24-41)$ & $26(22-30)$ & $0.062^{*}$ \\
\hline \multicolumn{6}{|l|}{ Sex $(\%)$} \\
\hline Female & $7(100)$ & $17(89.5)$ & $13(81.3)$ & $17(77.3)$ & $0.300^{* *}$ \\
\hline Male & $0(0)$ & 2 (10.5) & $3(18.8)$ & $5(22.7)$ & \\
\hline \multicolumn{6}{|l|}{ Marital status (\%) } \\
\hline Married & $0(0)$ & $3(15.8)$ & 5 (31.3) & $3(13.6)$ & $0.272^{* *}$ \\
\hline Single & $7(100)$ & $14(73.7)$ & $9(56.3)$ & 18 (81.8) & \\
\hline Divorced & $0(0)$ & $2(10.5)$ & $2(12.5)$ & $1(4.5)$ & \\
\hline \multicolumn{6}{|l|}{ Educational level (\%) } \\
\hline Less than high school & $0(0)$ & $1(5.3)$ & $1(6.3)$ & $0(0)$ & $0.007^{* *}$ \\
\hline Completed high school & $4(57.1)$ & $9(47.4)$ & $4(25)$ & $3(13.6)$ & \\
\hline Incomplete high school & $0(0)$ & $0(0)$ & $2(12.5)$ & $0(0)$ & \\
\hline Completed university & $0(0)$ & $3(15.8)$ & $6(37.5)$ & 9 (40.9) & \\
\hline Incomplete university & $3(42.9)$ & $5(26.3)$ & $1(6.3)$ & $6(27.3)$ & \\
\hline Graduate degree completed & $0(0)$ & $1(5.3)$ & $2(12.5)$ & $4(18,2,5)$ & \\
\hline Inactive work & $2(28.6)$ & $5(26.3)$ & $5(31.3)$ & $0(0)$ & $0.009^{* *}$ \\
\hline
\end{tabular}

Group A: Anorexia nervosa (restricting subtype); Group B: Anorexia nervosa (purging subtype); Group C: Bulimia nervosa; Group D: Control; ${ }^{*}$ Kruskal-Wallis test; ${ }^{* *}$ Likelihood test. 
Noncarious cervical lesions (NCCLs) were prevalent in $57 \%$ of ED patients, with significant differences when compared with group D $(p=0.03)$.

Complaints of pain in ED patients were as follows: facial pain $54.7 \%(n=23)$; earache $50 \%(n=21)$; sore throat 23.8\% ( $n=10)$; headache $52.3 \%(n=22)$; burning in the mouth $26.2 \%(n=11)$; pain in other regions of the body $45.23 \%(n=19)$ (Table 3$)$.

Although there was no statistical difference between groups $\mathrm{A}, \mathrm{B}$, and $\mathrm{C}$, there were significant differences $(p<0.004)$ between these groups and group $D$, and complaints of pain were more prevalent in individuals with ED. Patients in group C (56.3\%) were the ones with the most frequent complaints of facial pain, at sites such as the cheeks (jaws), sides of the head, in front of the ear, or in the ear in the last 4 weeks, followed by group B (52.6\%).

Fifty-nine patients were assessed according to Axis I of the RDC/TMD questionnaire. In the diagnosis of temporomandibular disorders, the groups exhibited statistical differences regarding muscle disorders $(p=0.010)$ (Table 4) and other joint changes on the left side $(p=0.006)$.

Table 2. General characteristics of ED patients (duration of disease, psychiatric comorbidities, use of medication, and use of illicit drugs) ( $\mathrm{n}=42)$.

\begin{tabular}{|c|c|c|c|c|}
\hline Variable & Group A $(n=7)$ & Group B $(n=19)$ & Group C $(n=16)$ & $P^{*}$ \\
\hline Duration $(<10$ y) & $4(57 \%)$ & $6(31.5 \%)$ & $5(31.4 \%)$ & $<0.001$ \\
\hline Duration (10-20 y) & $0(0 \%)$ & $6(31.6 \%)$ & 8 (50\%) & \\
\hline Duration (> 20 y) & $3(42.9 \%)$ & $7(36.8 \%)$ & $3(18.8 \%)$ & \\
\hline Use of laxative & $0(0 \%)$ & $4(21.1 \%)$ & $3(18.8 \%)$ & 0.241 \\
\hline Use of diuretics & $0(0 \%)$ & $4(21.1 \%)$ & $1(6.3 \%)$ & 0.163 \\
\hline Depression & $5(71.4 \%)$ & $4(28.6 \%)$ & $4(25 \%)$ & 0.088 \\
\hline Obsessive-compulsive disorder & $1(16.7 \%)$ & $2(14.3 \%)$ & $0(0 \%)$ & 0.152 \\
\hline Borderline personality disorder & $0(0 \%)$ & $3(21.4 \%)$ & $3(20 \%)$ & 0.637 \\
\hline Benzodiazepine dependence & $0(0 \%)$ & 1 (50\%) & $1(50 \%)$ & 0.351 \\
\hline Rumination & $3(42.9 \%)$ & $6(31.6 \%)$ & $8(50 \%)$ & 0.535 \\
\hline Alcoholism & $0(0 \%)$ & $1(5.3 \%)$ & $2(12.5 \%)$ & 0.423 \\
\hline Smoking & $1(14.3 \%)$ & $4(21.1 \%)$ & $5(31.3 \%)$ & 0.627 \\
\hline Illicit drugs & $0(0 \%)$ & $2(10.5 \%)$ & $1(6.3 \%)$ & 0.510 \\
\hline
\end{tabular}

Group A: Anorexia nervosa (restricting subtype); Group B: Anorexia nervosa (purging subtype); Group C: Bulimia nervosa; y - year; ${ }^{*}$ Likelihood test.

Table 3. Complaints of pain according to the standardized EDOF-HC evaluation $(n=64)$.

\begin{tabular}{lccccc}
\hline Pain complaints & Group A $(n=7)$ & Group B $(n=19)$ & Group C $(n=16)$ & Group D $(n=22)$ & $P^{*}$ \\
\hline Face & $5(71.4 \%)$ & $9(47.4 \%)$ & $9(56.3 \%)$ & $2(9.1 \%)$ & 0.001 \\
Ear & $4(57.1 \%)$ & $8(44.4 \%)$ & $9(56.3 \%)$ & $1(4.54 \%)$ & 0.001 \\
Throat & $0(0 \%)$ & $3(15.8 \%)$ & $7(43.8 \%)$ & $3(13.6 \%)$ & 0.036 \\
Head & $5(71.4 \%)$ & $8(44.4 \%)$ & $9(56.3 \%)$ & $1(4.54 \%)$ & 0.002 \\
Burning in the mouth & $0(0 \%)$ & $8(42.1 \%)$ & $3(18.8 \%)$ & $0(0 \%)$ & 0.005 \\
Other regions of the body & $5(71.4 \%)$ & $7(38.8 \%)$ & $7(43.8 \%)$ & $1(4.54 \%)$ & 0.003 \\
\hline
\end{tabular}

Group A: Anorexia nervosa (restricting subtype); Group B: Anorexia nervosa (purging subtype); Group C: Bulimia nervosa; Group D: Control; *Likelihood test

Table 4. Distribution of groups per diagnosis of myofascial pain according to Axis I of the RDC/TMD questionnaire $(n=59)^{*}$.

\begin{tabular}{|c|c|c|c|c|c|}
\hline RDC/TMD Axis I-Diagnosis & Group A ( $n=7)$ & Group B (n=16) & Group C (n = 14) & Group D (n = 22) & $P^{* *}$ \\
\hline \multicolumn{6}{|l|}{ Muscle disorders } \\
\hline Myofascial pain & $2(28.6 \%)$ & $3(18.8 \%)$ & $6(42.9 \%)$ & $2(9.1 \%)$ & 0.010 \\
\hline Myofascial pain with limited opening & $0(0 \%)$ & $3(18.8 \%)$ & $3(21.4 \%)$ & $0(0 \%)$ & \\
\hline
\end{tabular}

Group A: Anorexia nervosa (restricting subtype); Group B: Anorexia nervosa (purging subtype); Group C: Bulimia nervosa; Group D: Control;

*Five patients did not answer this part of the questionnaire; ${ }^{* *}$ Likelihood test 
There were differences in the presence of myofascial pain according to marital status when only ED patients were analyzed as to the presence or not of myofascial pain (RDC/TMD questionnaire, Axis I), as shown in Table 5. There were no differences in age, sex, and educational level.

Table 6 shows differences in the presence of myofascial pain and the number of hospitalizations $(p=0.046)$ and in the presence of sore throat $(p=0.05)$.

There was no difference between myofascial pain and duration of ED in years ( $p=0.425$ ) (Table 6).

The groups did not differ as to the presence of myofascial pain in terms of DMF index $(p=0.579)$.

According to the RDC/TMD questionnaire (Axis II), patients in groups $\mathrm{A}, \mathrm{B}$, and $\mathrm{C}$ showed no differences

Table 5. Comparison between ED groups with and without myofascial pain in relation to demographic and general characteristics ( $n=37)$.

\begin{tabular}{|c|c|c|c|}
\hline \multirow{2}{*}{$\begin{array}{l}\text { Demographic and general } \\
\text { characteristics }\end{array}$} & \multicolumn{2}{|c|}{ Myofascial pain } & \multirow{2}{*}{$P$} \\
\hline & No $(n=20)$ & Yes $(n=7)$ & \\
\hline Age (years) & $29(24-41)$ & $34(30-43)$ & $0.437^{*}$ \\
\hline Sex & & & $1.000^{* *}$ \\
\hline Female & $18(90 \%)$ & $15(88.2 \%)$ & \\
\hline Male & $2(10 \%)$ & $2(11.8 \%)$ & \\
\hline Marital status & & & $0.021^{* * *}$ \\
\hline Married & $2(10 \%)$ & $6(35.3 \%)$ & \\
\hline Single & $18(90 \%)$ & 9 (52.9\%) & \\
\hline Divorced & $0(0 \%)$ & 2 (11.8\%) & \\
\hline Educational level & & & $0.589^{* * *}$ \\
\hline Less than high school & $1(10 \%)$ & 1 (5.9\%) & \\
\hline Completed high school & $9(40 \%)$ & $6(35.3 \%)$ & \\
\hline Incomplete high school & $2(10 \%)$ & $0(0 \%)$ & \\
\hline Completed university & $4(20 \%)$ & $5(29.4 \%)$ & \\
\hline Incomplete university & $4(20 \%)$ & $3(17.6 \%)$ & \\
\hline Graduate degree completed & $0(0 \%)$ & 2 (11.8\%) & \\
\hline
\end{tabular}

in depressive symptoms $(p=0.097)$, although major depression was more prevalent in group B $(88.20 \%)$ and physical symptoms including and excluding the presence of "pain" exhibited p values of 0.509 and 0.693 , respectively. However, these diagnoses were absent in group $\mathrm{D}$, thus differing statistically from the other groups $(p<0.001)$.

Axis II of the RDC/TMD questionnaire shows that $73.5 \%$ of the patients who presented myofascial pain in Axis I showed low disability, ranging from low to high intensity, while $26.2 \%$ had high disability, ranging from moderate to severe. The results are outlined in Table 7.

Table 6. Comparison between ED groups with and without myofascial pain in relation to the number of vomiting episodes, hospitalization, ED duration, NCCL, and sore throat ( $n=37)$.

\begin{tabular}{|c|c|c|c|}
\hline \multirow{2}{*}{ Clinical features } & \multicolumn{2}{|c|}{ Myofascial pain } & \multirow{2}{*}{$P$} \\
\hline & No $(n=20)$ & Yes $(n=17)$ & \\
\hline Self-induced vomiting & $14(70 \%)$ & $14(82.4 \%)$ & $0.462^{*}$ \\
\hline It has been hospitalized & $16(80 \%)$ & $12(70.6 \%)$ & $0.703^{*}$ \\
\hline Number of hospitalizations & & & $0.046^{* *}$ \\
\hline 0 & $4(20 \%)$ & $5(29.4 \%)$ & \\
\hline 1 & $3(15 \%)$ & $5(29.4 \%)$ & \\
\hline 2 & $4(20 \%)$ & $5(29.4 \%)$ & \\
\hline 3 & $3(15 \%)$ & $0(0 \%)$ & \\
\hline 4 & $1(5 \%)$ & $0(0 \%)$ & \\
\hline 5 & $0(0 \%)$ & $2(11.8 \%)$ & \\
\hline 6 & $3(15 \%)$ & $0(0 \%)$ & \\
\hline 7 & 1 (5\%) & $0(0 \%)$ & \\
\hline 20 & $1(5 \%)$ & $0(0 \%)$ & \\
\hline Rumination & $8(40 \%)$ & $6(35.3 \%)$ & $0.769^{* * *}$ \\
\hline Duration (< 10 y) & $10(50 \%)$ & $4(23.5 \%)$ & \\
\hline Duration (10-20 y) & 4 (20\%) & 7 (41.1\%) & $0.425^{* *}$ \\
\hline Duration (> 20 y) & $6(30 \%)$ & $6(35.3 \%)$ & \\
\hline $\mathrm{NCCL}$ & 11 (55\%) & $11(68.8 \%)$ & 0.400 \\
\hline Sore throat & $2(10 \%)$ & 7 (41.2\%) & 0.050 \\
\hline $\mathrm{BMI}$ & $20.1 \pm 4.3$ & $23.4 \pm 8.6$ & 0.268 \\
\hline
\end{tabular}

${ }^{*}$ Fisher's exact test; * Likelihood test; ${ }^{* * *}$ Chi-square test.

Table 7. Classification of ED groups according to the degree of chronic pain, disability, and intensity by the RDC/TMD questionnaire (Axis II) $\left(\mathrm{n}=39^{* *}\right)$.

\begin{tabular}{|c|c|c|c|c|}
\hline Chronic pain grade & Group A ( $n=7)$ & Group B ( $n=17)$ & Group C (n = 15) & $\mathrm{P}^{* * *}$ \\
\hline Grade 0* & 5 (71.4\%) & $9(52.9 \%)$ & $6(40 \%)$ & 0.292 \\
\hline \multicolumn{5}{|l|}{ Low disability } \\
\hline Grade I - Low intensity & $0(0 \%)$ & $1(5.9 \%)$ & $5(33.3 \%)$ & \\
\hline Grade II - High intensity & $2(28.6 \%)$ & $4(23.5 \%)$ & $2(13.3 \%)$ & \\
\hline \multicolumn{5}{|l|}{ High disability } \\
\hline Grade III - Moderately limiting & $0(0 \%)$ & $2(11.8 \%)$ & $1(6.7 \%)$ & \\
\hline Grade IV - Severely limiting & $0(0 \%)$ & $1(5.9 \%)$ & $1(6.7 \%)$ & \\
\hline
\end{tabular}

Group A: Anorexia nervosa (restricting subtype); Group B: Anorexia nervosa (purging subtype); Group C: Bulimia nervosa; ${ }^{*}$ Grade 0 includes ED patients without myofascial pain according to the RDC/TMD questionnaire; *** Likelihood test 


\section{Discussion}

The results of this study show a high prevalence of masticatory myofascial pain and complaints of chronic facial pain among ED patients, as previously described by many articles. ${ }^{11,13,14,22}$ However, in this study, we classified these patients according to their specific psychiatric diagnosis and we also evaluated them for the presence of pain in other regions of the body or in specific areas of the head, not just the face. There was also a high prevalence of complaints of pain in the ear, throat, mouth, head, and other regions of the body. It is possible that the different pain complaints found in our sample correlate with the diagnosis of myofascial pain (RDC/TMD). Muscle pain is often diffuse and results in central sensitization that may be persistent and may have multifactorial causes; in addition, the trigeminal system presents a complex network of neural interconnections, and craniofacial pain often has a diffuse pain pattern..$^{23,24,25}$ The complaints of burning in the mouth and headache require a specific approach that was not within the scope of the present study.

When only ED patients with and without myofascial pain were compared, there was a correlation between myofascial pain and marital status (more singles in the pain-free group), number of hospitalizations (patients with myofascial pain had fewer hospitalizations, $p=0.046$ ), and sore throat $(p=0.050)$. However, the explanation for these correlations is not clear. We can speculate that as time passes by the patient's clinical status worsens and his/her attention changes, or that at the beginning of the disease, the musculoskeletal system is more seriously affected and that it ends up adapting over time. The correlation with sore throat captures our attention because it can have multiple causes, especially in ED patients. Reduction in salivary flow could hinder swallowing and cause increased activity of the infrahyoid muscles and also of the digastric muscle. Clinically speaking, this could be a good indicator of this correlation, although future studies are necessary to clarify this association and its clinical relevance. There was no correlation of myofascial pain with NCCL, BMI, and self-induced vomiting. The latter is another interesting finding, as it is of relevance among chronic or healthy patients, but not among ED patients.

All of these data bring the issue of chronic pain in ED patients into focus, since the presence of pain in other parts of the body may increase the risk for TMD or orofacial pain, as suggested by OPPERA. ${ }^{26,27}$

According to Axis II of the RDC/TMD questionnaire, there was a significant difference in the presence of signs and symptoms of depression and non-specific symptoms among ED patients when compared to the control group, although there were no differences among ED subgroups. While it is demonstrated that these conditions do not cause disability or serious limitations on activities $(p=0.292)$, inactive work status is more prevalent among ED patients $(p=0.009)$. Patients with chronic pain have more complaints of depression and of other mood disorders. ${ }^{22,25,28}$ In our study, $30.9 \%$ of ED patients presented depression as comorbidity, according to the psychiatric diagnosis. This percentage is lower than that found in Axis II; however, it is important to point out that the questionnaire is a research tool and, therefore, it only points out signs and symptoms of a disease and does not make the clinical diagnosis. This is the likely reason for the difference in the percentage values.

Some limitations of this study are the small size of ED groups and the cross-sectional design, which captures cases at the time of evaluation. On the other hand, this study presented a very complex sample of ED patients. Almost one third of the patients had more than five years of illness, several hospitalizations, psychiatric comorbidities, and need for continued psychiatric and medical treatment. Thus, the important points were the use of the RDC/TMD questionnaire for diagnosis, since this instrument has good sensitivity and specificity, ${ }^{29}$ allowed assigning ED patients to three subgroups to investigate their possible correlation with TMD and complaints of facial pain, and evaluated pain complaints in other regions of the body.

From a clinical point of view, it is important to introduce measures that contribute to a deeper understanding of the patient's needs and to define more precisely which treatments are most suitable for each patient. It is important to remember that in any therapeutic decision, in addition to the suggestions of 
the professional team involved, the patient's opinion is also essential..$^{30}$ And he or she should receive technical explanations, based on available evidence, to make his/her decision. Given all the factors that lead to chronic facial pain and other dental complaints, it is important for dentists to consider all the characteristics in different subtypes of ED so that dental treatment may be more specific. At the same time, participation of the dentist in a multidisciplinary team for the treatment of ED is important.

In conclusion, according to the methodology used in this study, there was a higher prevalence of masticatory myofascial pain and complaints of pain, not only in the orofacial regions but also in other parts of the body, in patients with ED when compared to healthy individuals; however, there was no difference between ED (AN - restricting subtype, AN - purging subtype, and BN) subgroups. Patients may experience TMD and ED without any correlation between the two, although one may aggravate the

\section{References}

1. Aranha AC, Eduardo CP, Cordás TA. Eating disorders. Part I: psychiatric diagnosis and dental implications. J Contemp Dent Pract. 2008 Sep;9(6):73-81.

2. Hay PJ, Bacaltchuk J. Psychotherapy for bulimia nervosa and binging. Cochrane Database Syst Rev. 2003;(1):CD000562. https://doi.org/10.1002/14651858.CD000562

3. Hsu LK. Epidemiology of the eating disorders. Psychiatr Clin North Am. 1996 Dec;19(4):681-700. https://doi.org/10.1016/S0193-953X(05)70375-0

4. Nunes MA, Appolinario JC. Galvão AL, Coutinho W. Transtornos alimentares e obesidade. Rio de Janeiro: Artmed; 2006.

5. World Health Organization - WHO. Oral health surveys: basic methods. 4th ed. Genova: World Health Organization; 1997.

6. American Psychiatric Association. Diagnostic and statistical manual of mental disorders Fifth Edition (DSM-5). Washington, DC:: American Psychiatric Association; 2013.

7. Cordás TA. Transtornos alimentares: classificação e diagnóstico. Rev Psiquiatr Clin. 2004;31(4):154-7. https://doi.org/10.1590/S0101-60832004000400003

8. Kaplan HI, Saddock BJ. Compêndio de psiquiatria. Porto Alegre: Artmed; 2007.

9. Yager J, Powers P. Manual clínico de transtornos da alimentação. São Paulo: Artmed; 2010

10. Frydrych AM, Davies GR, McDermott BM. Eating disorders and oral health: a review of the other. Depression was a common comorbidity for these patients and there was no difference in the number of self-induced vomiting episodes between ED patients with and without myofascial pain. There is a need for further studies to better explain the relationship between these two clinical entities.

\section{Acknowledgments}

The authors express their thanks to the Eating Disorders Program of the Institute of Psychiatry (AMBULIM), the Orofacial Pain Team of Hospital das Clínicas of the Faculty of Medicine of the University of São Paulo (EDOF-HC), the Dental Clinic of the Institute of Psychiatry of the Hospital das Clínicas of the Faculty of Medicine of the University of São Paulo, and the National Council for the Improvement of Higher Education (CAPES). The authors also thank Professors Manoel Jacobsen Teixeira and Wagner F. Gattaz.

literature. Aust Dent J. 2005 Mar;50(1):6-15. https://doi.org/10.1111/i.1834-7819.2005.tb00079.x

11. Johansson AK, Johansson A, Unell L, Norring C, Carlsson GE. Eating disorders and signs and symptoms of temporomandibular disorders: a matched case-control study. Swed Dent J. 2010;34(3):139-47.

12. Lo Russo L, Campisi G, Di Fede O, Di Liberto C, Panzarella V, Lo Muzio L. Oral manifestations of eating disorders: a critical review. Oral Dis. 2008 Sep;14(6):479-84. https://doi.org/10.1111/j.1601-0825.2007.01422.x

13. Emodi-Perlman A, Yoffe T, Rosenberg N, Eli I, Alter Z, Winocur E. Prevalence of psychologic, dental, and temporomandibular signs and symptoms among chronic eating disorders patients: a comparative control study. J Orofac Pain. 2008;22(3):201-8.

14. Goldberg MB, Katzman DK, Woodside DB, Baker GI. Do eating disorders and chronic facial pain coexist? A preliminary study. J Can Dent Assoc. 2006 Feb;72(1):51.

15. Milosevic A, Slade PD. The orodental status of anorexics and bulimics. Br Dent J. 1989 Jul;167(2):66-70. https://doi.org/10.1038/si.bdj.4806915

16. Johansson AK, Johansson A, Nohlert E, Norring C, Åstrøm AN, Tegelberg A. Eating disorders - knowledge, attitudes, management and clinical experience of Norwegian dentists. BMC Oral Health. 2015 Oct;15(1):124. https://doi.org/10.1186/s12903-015-0114-7 
- Pain and temporomandibular disorders in patients with eating disorders

17. Siqueira JT, Lin HC, Nasri C, Siqueira SR, Teixeira MJ, Heir $G$ et al. Clinical study of patients with persistent orofacial pain. Arq Neuropsiquiatr. 2004 Dec;62(4):988-96. https://doi.org/10.1590/S0004-282X2004000600011

18. Pereira Junior FJ, Favilla EE, Dworkin S, Huggins K. Research diagnostic criteria for temporomandibular disorders (RDC) TMD): official translation for Portuguese language. J Bras Clin Odontol Integr. 2004;8(47):384-95.

19. Kominsky M, Lucena LBS, Siqueira JTT, Pereira Júnior F, Góes PSA. Adaptaçãoo cultural do Questionário Research Diagnostic Criteria for Temporomandibular Disorders: Axis II para o Português. J Bras Clin Odontol Integr. 2004;8(43):51-61.

20. Correr GM, Alonso RC, Correa MA, Campos EA, Baratto-Filho F, Puppin-Rontani RM. Influence of diet and salivary characteristics on the prevalence of dental erosion among 12-year-old schoolchildren. J Dent Child (Chic). 2009 Sep-Dec;76(3):181-7.

21. Rosner B. Fundamentals of biostatistics. 4th ed. New York: Duxbury Press; 1994.

22. Coughlin JW, Edwards R, Buenaver L, Redgrave G, Guarda AS, Haythornthwaite J. Pain, catastrophizing, and depressive symptomatology in eating disorders. Clin J Pain. 2008 Jun;24(5):406-14. https://doi.org/10.1097/AJP.0b013e3181633fc5

23. Sessle BJ. Acute and chronic craniofacial pain: brainstem mechanisms of nociceptive transmission and neuroplasticity, and their clinical correlates. Crit Rev Oral Biol Med. 2000;11:57-91. https://doi.org/10.1177/10454411000110010401.
24. Sessle BJ. Peripheral and central mechanisms of orofacial pain and their clinical correlates. Minerva Anestesiol. 2005 Apr;71(4):117-36.

25. de Siqueira SR, Vilela TT, Florindo AA. Prevalence of headache and orofacial pain in adults and elders in a Brazilian community: an epidemiological study. Gerodontology. 2015 Jun;32(2):123-31. https://doi.org/10.1111/ger.12063

26. Greenspan JD, Slade GD, Bair E, Dubner R, Fillingim RB, Ohrbach $R$ et al. Pain sensitivity risk factors for chronic TMD: descriptive data and empirically identified domains from the OPPERA case control study. J Pain. 2011 Nov; 12(11 Suppl):T61-74. https://doi.org/10.1016/i.jpain.2011.08.006

27. Maixner W, Diatchenko L, Dubner R, Fillingim RB, Greenspan $J D$, Knott $C$ et al. Orofacial pain prospective evaluation and risk assessment study - the OPPERA study. J Pain. 2011;12(11 Suppl):T4-11. e12. https://doi.org/10.1016/i.jpain.2011.08.002

28. Fillingim RB, Ohrbach R, Greenspan JD, Knott C, Diatchenko L, Dubner $R$ et al. Psychological factors associated with development of TMD: the OPPERA prospective cohort study. J Pain. 2013 Dec;14(12 Suppl):T75-90. https://doi.org/10.1016/i.jpain.2013.06.009.

29. Ohrbach R, Dworkin SF. The evolution of TMD diagnosis: past, present, future. J Dent Res. 2016 Sep;95(10):1093-101. https://doi.org/10.1177/0022034516653922

30. Szupiany T, Pyłko-Polończyk J, Rutkowski K. Dental needs of psychiatric patient with eating disorders. Psychiatr Pol. 2015;49(5):945-54. https://doi.org/10.12740/PP/OnlineFirst/35269 